\title{
Transposable elements in South American populations of Drosophila simulans
}

\author{
Elgion Lucio da Silva Loreto ${ }^{a}$, Arnaldo Zaha ${ }^{\mathrm{b}}$, \\ Vera Lucia da Silva Valente ${ }^{\text {** }}$ \\ a Departamento de Biologia, \\ Universidade Federal de Santa Maria, Santa Maria, RS, Brazil \\ b Departamento de Biotecnologia, \\ Universidade Federal do Rio Grande do Sul, Porto Alegre, RS, Brazil \\ c Departamento de Genética, Caixa Postal 15053, \\ Universidade Federal do Rio Grande do Sul, \\ CEP 91501-970, Porto Alegre, RS, Brazil
}

(Received 20 June 1997; accepted 27 January 1997)

\begin{abstract}
This study investigated the occurrence of four transposable elements (mariner, gypsy, hobo and 412) in South American populations of Drosophila simulans. The genomic hybridization patterns of 12 different populations were determined by Southern blot analyses. Even though a low number of mariner copies was observed, each population presented a characteristic hybridization pattern, suggesting that the element is active. The number of gypsy copies was also low, but all populations bore a similar hybridization pattern. In this paper we describe the occurrence of an almost gypsy-free strain, which had not yet been found for $D$. simulans nor $D$. melanogaster. In the case of hobo, we did not detect the 1.1-kb-long deleted hobo element in any of the South American populations while this element is present in all strains originating from other geographical sites that were analysed up to now, suggesting that the hobo element may have very recently invaded the genome of South American D. simulans populations. The 412 element presented some population-specific band patterns, indicating that this element may have some transposition activity in the different populations. (C) Inra/Elsevier, Paris
\end{abstract}

Drosophila simulans / transposable element / mariner / hobo / gypsy / 412

Résumé - Éléments transposables dans des populations sud-américaines de Drosophila simulans. Cette étude recherche la présence de quatre éléments transposables (mariner, gypsy, hobo et 412) au sein de populations sud-américaines de Drosophila simulans. Le profil d'hybridation génomique de 12 populations différentes a été déterminé par Southern

\footnotetext{
* Correspondence and reprints

E-mail: valente@if1.if.ufrgs.br
} 
Blot. Bien que seul un petit nombre de copies de mariner ait été observé, chaque population présentait un profil d'hybridation caractéristique, ce qui suggère que l'élément était actif. Le nombre de copies de l'élément gypsy s'est avéré très petit ; avec un profil d'hybridation similaire dans toutes les lignées, ce qui indique que l'élément était inactif dans les populations étudiées. L'une des lignées ne comportait pratiquement pas d'élément gypsy, ce qui n'était encore jamais arrivé chez $D$. simulans ni $D$. melanogaster. L'élément hobo de 1,1 kb n'a été détecté dans aucune lignée d'Amérique du Sud alors qu'il existe dans toutes les lignées, originaires d'autres sites géographiques, analysées jusqu'à présent. Ces informations en accord avec les données de la littérature, suggèrent que l'élément hobo n'a peut-être envahi que récemment le génome des populations de $D$. simulans en Amérique du Sud. Pour l'élément 412, les populations étudiées ont montré des bandes spécifiques, ce qui suggère que cet élément peut avoir des activités de transposition dans le génome de ces mouches. (c) Inra/Elsevier, Paris

Drosophila simulans / élément transposable / mariner / hobo / gypsy

\section{INTRODUCTION}

Transposable elements (TEs) have already been shown to compose a significant fraction of the genome of a wide variety of organisms [1]. Approximately $10 \%$ of the D. melanogaster genome consists of 50 different families of TEs [13]. The amount of middle repetitive DNA sequences in $D$. simulans was estimated to be about one third that present in its sibling species $D$. melanogaster [10]. It is believed that a major portion of this repetitive DNA is composed of TEs [26]. Virtually all families of TEs that have been cloned from $D$. melanogaster are also represented in the genome of $D$. simulans [6]. The only exception to the similar TE composition between the two species is the presence of the $P$ family, which is only found in $D$. melanogaster and mariner which is only found in D. simulans. Considering that virtually the same TE families are present in both species and that $D$. simulans has only one third the total repetitive DNA present in D. melanogaster, the mean number of element copies per family should be lower in $D$. simulans $[17,20,23]$. These last authors detected significant differences in copy number of TEs between those species by in situ hybridization.

Studies covering the whole distribution range of $D$. simulans should make it possible to better understand the differences in the number of copies of TEs between this species and $D$. melanogaster, in addition to providing important information on the evolutionary history of TEs. In an attempt to contribute to the resolution of this question, we investigated the occurrence of four different transposable element families (mariner, hobo, gypsy and 412), by means of Southern blot analyses, in 12 $D$. simulans populations originating from different locations within the American continent.

\section{MATERIALS AND METHODS}

\subsection{Fly stocks}

The following strains of $D$. simulans were employed in the present study: 1) Peru (obtained from Bowling Green Center - no. 14021-0251-5) - originally collected in 
Lima, Peru; 2) Salvador - collected in Salvador, Bahia - Brazil, in 1995; 3) RJ collected in the National Park of Tijuca, Rio de Janeiro - Brazil, in 1995; 4) SBC collected in São Bernardo do Campo, São Paulo - Brazil, in 1993; 5) MGS - collected in Eldorado, Mato Grosso do Sul - Brazil, in 1994; 6) Maquiné - collected in Maquiné, Rio Grande do Sul - Brazil, in 1994; 7) Goethe - collected in Porto Alegre, Rio Grande do Sul - Brazil, in 1991; 8) dpp-like - derived from a spontaneous mutant originating from in a hypermutable wild strain of $D$. simulans collected in Porto Alegre, Rio Grande do Sul - Brazil, in 1990; 9) yellow - derived from a spontaneous mutant of the yellow locus encountered in a population sample from Itapuã, Rio Grande do Sul - Brazil, in 1982; 10) Camobi - collected in Santa Maria, Rio Grande do Sul - Brazil, in 1994; 11) Montevideo - collected in Montevideo, Uruguay, in 1991; 12) 1093 (obtained from Caltech Center) - collected in Islamorada, Florida - USA.

\subsection{Southern blots}

Genomic DNA was prepared from 40-50 adult flies, according to Jowett [16]. DNA samples (approximately $5 \mu \mathrm{g}$ from each strain) were completely digested with restriction endonucleases, submitted to electrophoresis on $0.8 \%$ agarose gels, transferred to nylon membranes and hybridized to nick-translated DNA probes (labeled with ${ }^{32} \mathrm{P}$ - $\alpha$-dATP) in the presence of $50 \%$ formamide at $42{ }^{\circ} \mathrm{C}$. Each filter was washed three times with $0.2 \mathrm{X}$ SSC and $0.5 \%$ SDS for $20 \mathrm{~min}$ at $42^{\circ} \mathrm{C}$.

A 0.9-kb fragment obtained by NheI/PvuII digestion of Mos 1 plasmid DNA [19] was used as a probe for the analysis of the mariner TE family. As a probe for the gypsy element, we employed the pGGHS plasmid, which contains a complete gypsy element [9]. Members of the hobo family were probed with the pHX4 plasmid, which contains a XhoI 2.6-kb fragment of hobo element of D. melanogaster. The 2.6-kb fragment was removed from a complete element contained in the pHLF1 plasmid [4] and subcloned into the Bluescript plasmid. The probe used to detect 412, was an element four HindIII-EcoRI fragment from $\mathrm{cDm} 412$ with a total length of $4.4-\mathrm{kb}$ was used [27].

\section{RESULTS}

\subsection{Southern blot analyses}

\subsubsection{Mariner family}

When the DNAs from $D$. simulans populations of diverse geographical origins were hybridized to the mariner element probe, we observed hybridization patterns that were characteristic to each one of them. The mean number of hybridizing bands varied according to the restriction enzyme used. For instance, when D. simulans DNA was digested with $S a l I$, we saw, on average, $9.0 \pm 4.1$ hybridizing bands (see figure $1 \mathrm{~A}$ ). The yellow strain presented the largest number of hybridization bands (16 bands); the Montevideo population presented the smallest number (one band). Since the mariner element possesses a single site for $S a l I$, we expected each copy of the element to produce two hybridization bands when the genomic DNA was 
digested with this enzyme. The number of copies per genome should have been equal to approximately half the number of observed bands. Enzymes that do not have internal sites in the mariner element sequence would yield a smaller number of bands, which should correspond to the approximate number of copies of the element. When DNA was digested with $\mathrm{XhoI}$, for example, the number of hybridizing bands was on average $4.4 \pm 1.5$. Once again, the yellow strain was the one with the largest number of bands (a total of nine) which were not seen in this Southern, but have been observed in other experiments (data not shown). Maquiné and 1093 were the ones showing the smallest number (only three hybridization bands) (figure 1B).
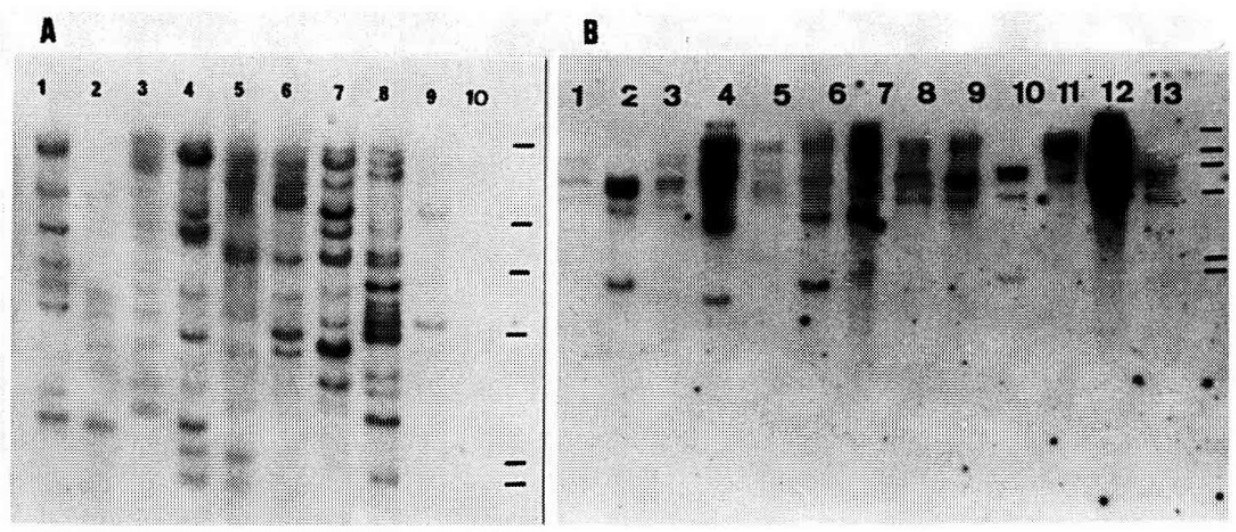

Figure 1. Southern blots of D. simulans populations hybridized to a $0.9-\mathrm{kb}$ fragment obtained by NheI/PvulI digestion of Mos1 plasmid used as a mariner probe. A) Genomic DNA digested with Sall. The samples are as follows: 1) Peru, 2) Salvador, 3) RJ, 4) SBC, 5) MGS, 6) Camobi, 7) Maquiné, 8) yellow, 9) Goethe, 10) Montevideo. B) Genomic DNA digested with XhoI. The populations are as follows: 1) H134-18, 2) 1093, 3) Peru, 4) Salvador, 5) RJ, 6) SBC, 7) MGS, 8) Maquiné, 9) Camobi, 10) $d p p$-like, 11) Goethe, 12) yellow, 13) Montevideo. Bars on the right represent the $\lambda$ HindIII fragments $(24,9.5,6.8$, $4.3,2.3$ and $2.0 \mathrm{~kb}$ ).

\subsubsection{Hobo family}

The cleavage sites for $X h o I$ in the hobo element are close to the inverted terminal repeats, and digestion with this enzyme yields a 2.6 -kb-long fragment when a complete hobo copy is present, and smaller bands if deleted elements are present. All strains analysed possessed the 2.6 - $\mathrm{kb}$ band, indicating the occurrence of complete elements (figure 2). Boussy and Daniels [5] have shown the occurrence of a 0.7-kb band (corresponding to a deleted element very common in D. simulans) in the majority of the strains they analysed. In the present study, we detected this band in the North American strains (1093), but we did not find it in any of the South American populations.

Some strains, such as $d p p$ and yellow presented a very weak signal for the $2.6-\mathrm{kb}$ band, indicating that possibly only a few copies of the complete element were present in these strains. 
Bands greater than $2.6 \mathrm{~kb}$, as seen in figure 2, were also encountered in other species of the melanogaster subgroup. According to Boussy and Daniels [5] the occurrence of such bands can be explained by the presence of other TEs which carry sequences related to hobo. Hobo elements bearing a deleted or altered XhoI site are also interpreted as old sequences of hobo localized in heterochromatin.

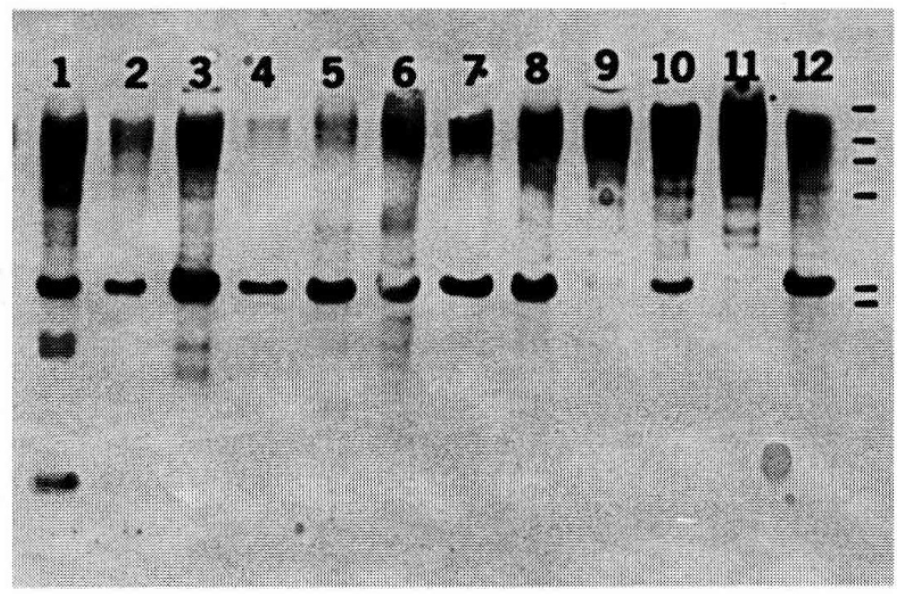

Figure 2. Screen for potentially complete hobo elements of $D$. simulans populations Genomic DNA was digested with XhoI and probed with pHX4. Samples are as follows: 1) 1093, 2) Peru, 3) Salvador, 4) RJ, 5) SBC, 6) MGS, 7) Maquiné, 8) Camobi, 9) $d p p-$ like, 10) Goethe, 11) yellow, 12) Montevideo. Bars on the right represent the 1 HindIII fragments $(24,9.5,6.8,4.3,2.3$ and $2.0 \mathrm{~kb})$.

\subsubsection{Gypsy family}

Hybridizing the membranes to the gypsy element probe resulted in a small number of hybridization bands, with an average of $7.8 \pm 2.8$ bands. A highly conserved hybridization pattern was observed throughout the $D$. simulans populations. When the fly DNA was digested with $S a I I$ or EcoRI, the majority of the bands was common to almost all populations - few bands were specific to each population (figure 3). Based on the known sequence of $D$. melanogaster's gypsy, this element should have a single cleavage site for $E c o$ RI and none for $S a l l$. Therefore, if we assume the same element structure for gypsy of $D$. simulans, we might have expected to see different hybridization bands among the different studied populations in the case of the occurrence of insertion site polymorphism.

The yellow strain was an important exception. It seemed to bear very few copies of gypsy in its genome, as can be seen in figure $3 A$ (lane 8 ). It should be noted that the Southern membrane shown in figure $3 A$ is the same as the one used in figure $1 A$, where yellow was one of the strains showing the largest number of hybridized bands with the mariner element. 


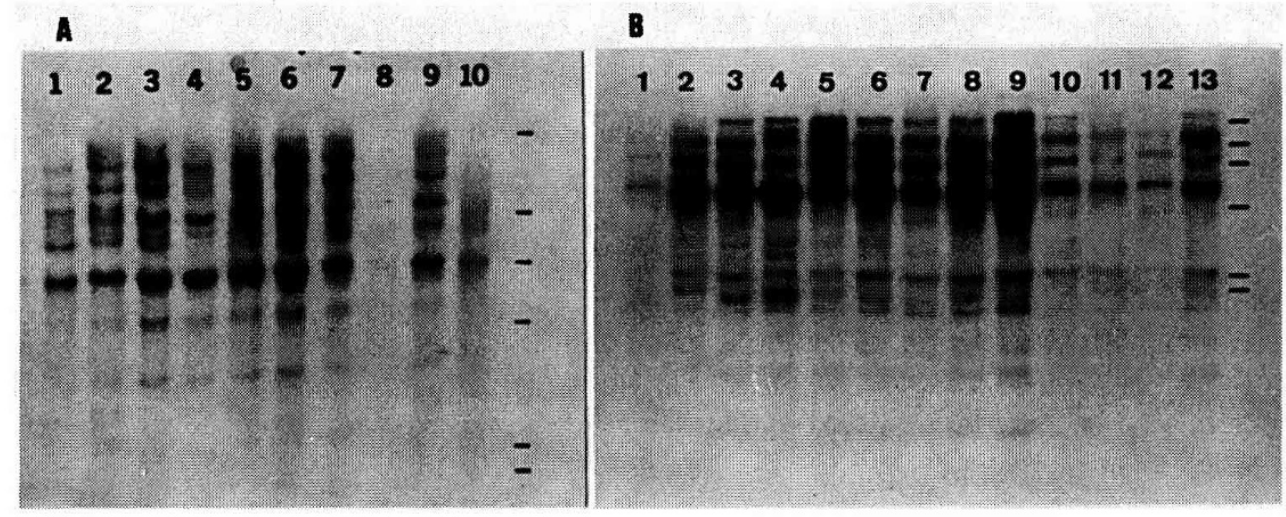

Figure 3. Southern blots of DNA from $D$. simulans strains hybridized to the gypsy element. A) Genomic DNA of $D$. simulans populations digested with Sall. The populations are as follows: 1) Peru, 2) Salvador, 3) RJ, 4) SBC, 5) MGS, 6) Camobi, 7) Maquiné, 8) yellow, 9) Goethe, 10) Montevideo; B) Genomic DNA of $D$. simulans populations digested with EcoRI. The populations are as follows: 1) yellow, 2) Montevideo, 3) Camobi, 4) $d p p-$ like, 5) Goethe, 6) Maquiné, 7) SBC, 8) MGS, 9) RJ, 10) Salvador, 11) Peru, 12) H143-18, 13) 1093. Bars on the right represent the $\lambda$ HindIII fragments $(24,9.5,6.8,4.3,2.3$ and and $2.0 \mathrm{~kb})$.

\subsubsection{2 family}

The 412 element of $D$. melanogaster carries four XhoI restriction sites [27]. We thus expected to obtain bands corresponding to $2.6,2.1$ and $0.9-\mathrm{kb}$ in size in the presence of a complete copy of 412. As shown in figure 4A, all the analysed populations carried the expected bands, in addition to greater-sized bands, some of which were specific for each population.

The 1.4- and 0.6-kb fragments expected with an EcoRI digestion were found in all populations, in addition to greater-sized bands, some of which were specific for each population (figure $4 B$ ).

\section{DISCUSSION}

Capy et al. [8], Maruyama and Hartl [18] and Giraud and Capy [14] have analysed several $D$. simulans populations by Southern Blot, and their results showed that the number of mariner copies per genome varies from 0 to 15 . Our present findings on the number of mariner copies occurring in the genome of $D$. simulans, as inferred from the number of bands encountered in the Southern blot assays, were very much in agreement with values found in previous studies about the occurrence of mariner in strains of this species from other origins.

Maruyama and Hartl [18] have detected hybridization bands that are specific for each strain, indicating the existence of insertion site polymorphism for the mariner element. Nevertheless, these authors have also observed some genomic sites common 
A

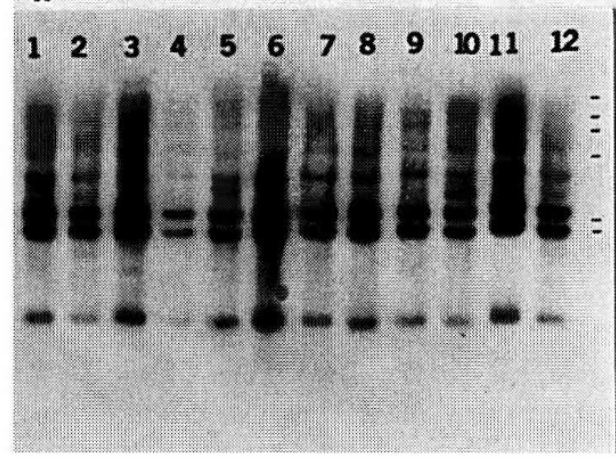

B

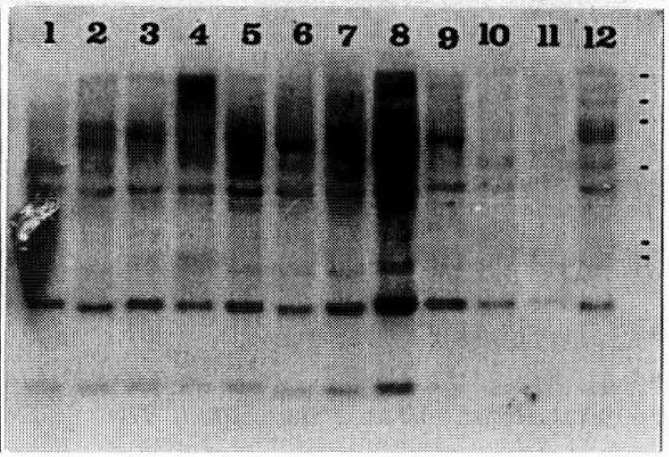

Figure 4. Southern blots of $D$. simulans populations probed with four HindIII-EcoRI fragments from a cDm412 plasmid (412 element). A; Genomic DNA of $D$. simulans populations digested with $X$ hoI. The samples are as follows: 1) 1093, 2) Peru, 3) Salvador, 4) RJ, 5) SBC, 6) MGS, 7) Maquiné, 8) Camobi, 9) dpp-like, 10) Goethe, 11) yellow, 12) Montevideo. B; Genomic DNA digested with EcoRI. The samples are as follows: 1) Montevideo, 2) Camobi, 3) $d p p$-like, 4) Goethe, 5) Maquiné, 6) SBC, 7) MGS, 8) RJ, 9) Salvador, 10) Peru, 11) H134-18, 12) 1093. Bars on the right represent the $\lambda$ HindIII fragments $(24,9.5,6.8,4.3,2.3$ and $2.0-\mathrm{kb})$.

to strains from diverse geographical origins, indicating that at least some of them are long-existing insertion sites and may be fixed within the species. Giraud and Capy [14] described three banding patterns in mariner Southern blot analysis: i) populations from different geographical origins which share the same three bands, these populations having few bands; ii) populations with more bands, some of these common to all the lines of a population; iii) populations with few bands different among populations. In the present study, we did not find any hybridization bands common to the different populations; each population showed a characteristic hybridization profile, in agreement with Giraud and Capy's pattern 3.

Laboratory populations show greater variability in mariner copy number than natural populations [15]. This fact might explain the high copy number occurring in our yellow strain, as this population has been kept in the laboratory since 1982. All South American strains employed in the present study were recently collected in the wild, except for the yellow and $d p p$-like strains, and none of them were mariner-free. This apparent non-existence of mariner-free populations among recently collected ones is also supported by the findings of Capy et al. [8] and Giraud and Capy [14].

Periquet et al. [21] recorded the fact that almost all natural populations of D. melanogaster possess copies of a 1.5 -kb-long internally deleted hobo element. They called this element $T h$. These authors suggest that the accumulation of these $T h$ elements in the genome might have some regulatory role in hobo transposition. Such a role has been suggested for the KP element of the $P$ family of $D$. melanogaster [3]. Boussy and Daniels [5] analysed 19 D. melanogaster and 31 D. simulans strains by Southern blot. $\mathrm{E}$ (empty of hobo) and $\mathrm{H}$ (with hobo) strains 
were found in both species. In several $D$. melanogaster strains they observed the occurrence of the 1.5-kb $(T h)$ element. In $D$. simulans, only four strains (one from Peru; one from Colombia; and one of unknown origin) did not have the hybridization band that indicates the presence of a complete element. The three South American strains also did not bear the $0.7-\mathrm{kb}$ band that corresponds to an internally deleted element of $1.1 \mathrm{~kb}$. All other strains, originating from North America, Australia and South Africa, as well as the one with unknown origin, showed a very strong hybridization signal corresponding to the $0.7-\mathrm{kb}$ band.

In the present study, we found two $D$. simulans strains with very weak hybridization signals for the $2.6-\mathrm{kb}$ band (the existence of which represents the occurrence of a complete element), indicating that these strains carry few copies of the hobo element. Such strains have been kept in the laboratory for a longer period of time (14 and 6 years) than all the other populations, which were recently collected in nature and have strong hybridization signals for the $2.6-\mathrm{kb}$ band. Furthermore, the 0.7-kb band (corresponding to an internally deleted element) was encountered only in the two North American populations; all the South American populations are devoid of this element. Considering our findings of few hobo sequences in older fly stocks and the results obtained by Boussy and Daniels [5], as a whole, we may suggest that hobo has been recently scattered in the genome of South American populations of $D$. simulans. Another argument in favor of this possible event is the reduced number of copies of deleted elements in the South American populations, most of all, the absence of the 1.1-kb elements which are so common to populations of other geographical origins. If the deleted elements do accumulate in the genome as a function of time after invasion, and if they are truly involved in the regulation of hobo activity [11], then we might suppose that hobo is active in the South American populations of $D$. simulans but not enough time has elapsed for a sufficient accumulation of deleted hobo copies in their genomes.

All $D$. melanogaster strains contain inactive copies of gypsy located at the same positions in the pericentromeric heterochromatin [22]. Even non-related strains, when compared by Southern blot analysis, show very similar hybridization patterns, suggesting that the gypsy element has invaded the genome of $D$. melanogaster very early in the species evolutionary history [7]. Nevertheless, a low copy number of putative active gypsy with no fixed sites were detected by in situ hydridization in D. melanogaster chromosomes arms [2,23] and in D. simulans [23].

The South American populations of $D$. simulans presently examined bear very similar hybridization patterns, in the same way as $D$. melanogaster strains carrying few gypsy copies do. According to our estimates, as judged by the number of Southern hybridization bands, South American populations of D. simulans also bear a reduced number of gypsy copies. However, this Southern pattern may represent the ancient inactive copies of gypsy in the heterochromatin. If there exist active copies of gypsy in a low number in polymorphic insertions sites, these can be related to the weak bands specifically detected in some populations or these copies were not able to be detected by the Southern technique, since every individual presents one specific band.

In $D$. melanogaster, there is no evidence of a strain not presenting a hybridization signal when probed by gypsy sequences. Our finding of a $D$. simulans strain almost devoid of gypsy copies is most interesting. This strain has been kept in the laboratory 
for 14 years. Stochastic loss [12] may be an explanation for the extremely low number of gypsy sequences it carries. This hypothesis is supported by the fact that all other studied strains that were derived from recently collected population samples do possess the gypsy element.

The 412 element is a retrotransposon, $7.6 \mathrm{~kb}$ in length, with 481-pb-long LTRs [27]. This element, similar to other retrotransposons, has apparently been inhabiting the genome of drosophilids for a very long period of time. Vieira and Biémont [24, $25]$ determined, by in situ hybridization to polytene chromosomes, the number of copies of the 412 element occurring in natural populations of $D$. simulans. A gradient in copy number was observed, varying from 20 in Europe, to 3-9 in Africa, with the same tendencies between North and South America. Some transposition bursts were observed within certain local populations that possess a high copy number of 412. These authors suggest this element has recently invaded the genome of $D$. simulans populations.

In the present study we observed that all the studied populations carried copies of an apparently complete 412 element, and that the EcoRI and XhoI sites were conserved in relation to the $D$. melanogaster 412 element. The occurrence of a few bands that were characteristic of each strain may suggest that this element is active in South American D. simulans populations.

\section{ACKNOWLEDGEMENTS}

This research was supported by grants and fellowships of CNPq, CAPES, FINEP, PROPESP-UFRGS and FAPERGS (grant number 931017.6). We would like to express our gratitude to Drs D. Hartl, D. Dorsett, R. Blackman and P. Sniegowsky for gifts of TE clones; to C. Rohde, L. Basso and O. Crosa for collecting the flies strains and to J. Rodrigues and L.P. Regner for suggestions. We are also grateful to the two anonymous reviewers for their valuable suggestions.

\section{REFERENCES}

[1] Berg D.E., Howe M.M., Mobile DNA, Am. Soc. Microbiol, Washington, DC, 1989.

[2] Biémont C., Lemeunier F., Garcia Guerreiro M.P., Brookfield J.F., Gautier C., Aulard S., Pisyukova E.G., Population dynamics of the copia, mdg1, mdg3, gypsy and P transposable elements in a natural population of Drosophila melanogaster, Genet. Res. 63 (1994) 197-212.

[3] Black D.M., Jackson M.S., Kidwell M.G., Dover G.A., KP elements repress $\mathrm{P}$-induced hybrid dysgenesis in D. melanogaster, EMBO 6 (1987) 4125-4135.

[4] Blackman R.K., Macy M., Koehler D., Grimaila R., Gelbart, W.M., Identification of a fully-functional hobo transposable element and its use for germ-line transformation of Drosophila, EMBO 8 (1989) 211-217.

[5] Boussy I.A., Daniels S.B., Hobo transposable elements in Drosophila melanogaster and D. simulans, Genet. Res. 58 (1991) 27-34.

[6] Brookfield J.F.Y., Montgomery E., Langley C., Apparent absence of transposable elements related to the $\mathrm{P}$ elements of $D$. melanogaster in other species of Drosophila, Nature 310 (1984) 330-332.

[7] Bucheton A., The relationship between the flamenco gene and gypsy in Drosophila: how to tame a retrovirus, Trends Genet. 11 (1995) 349-353. 
[8] Capy P, David J.R., Hartl D.L., Evolution of the transposable element mariner in the Drosophila melanogaster species group, Genetica 86 (1992) 37-46.

[9] Dorsett D., Viglianti G.A., Rutledge B.J., Meselson M., Alteration of hsp82 gene expression by the gypsy transposon and supressor genes in D. melanogaster, Genes Dev. 3 (1989) 454-468.

[10] Dowsett A.P., Young M.W., Differing levels of dispersed repetitive DNA among closely related species of Drosophila, Proc. Nat. Acad. Sci. USA 79 (1982) 4570-4574.

[11] Engels W.R., Hybrid dysgenesis in Drosophila and the stochastic loss hypothesis, Cold Spring Harbor Symp. Quant. Biol. 45 (1981) 561-565.

[12] Engels W.R., $P$ element in Drosophila melanogaster, in: Berg D.E., Howe M.M., (Eds.), Mobile DNA, Am. Soc. Microbiol., Washington, DC, 1989, pp. 437-484.

[13] Finnegan D.J., Transposable elements, in: Lindsley D.L., Zinn G.G. (Eds.), The Genome of Drosophila melanogaster, Acad. Press, San Diego, 1992, pp. 1096-1107.

[14] Giraud T., Capy P., Somatic activity of the mariner transposable element in natural population of Drosophila simulans, Proc. R. Soc. Lond. B 263 (1996) 1481-1486.

[15] Hartl D.L., Transposable element mariner in Drosophila species, Berg D.E., Howe M.M. (Eds.), Mobile DNA Am. Soc. Microbiol., Washington, DC, 1989, pp. 531-536.

[16] Jowett T., Preparation of nucleic acids, in: Roberts D.B. (Ed.), Drosophila: a Practical Approach, IRL Press, Washington, DC, 1986, pp. 275-286.

[17] Leibovitch B.A., Glushkova E.G., Pasyukova E.G., Belyaeva E.S., Gvozdev V.A., Comparative analysis of retrotransposon localization and mobility in sibling species Drosophila simulans and Drosophila melanogaster, Genetika 28 (1992) 85-97.

[18] Maruyama K., Hartl D.L., Evolution of the transposable element mariner in Drosophila species, Genetics 128 (1991) 319-329.

[19] Medhora M., Maruyama K., Hartl D.L., Molecular and functional analysis of the mariner mutator element Mos 1 in Drosophila, Genetics 128 (1991) 311-318.

[20] Nuzhdin S.V., The distribution of transposable elements on X chromosomes from a natural population of Drosophila simulans, Genet. Res. 66 (1995) 159-166.

[21] Periquet G., Hamelin M.H., Bigot Y., Hu K., Presence of the deleted hobo element Th in Eurasian populations of Drosophila melanogaster, Genet. Sel. Evol. 21 (1989) 107111.

[22] Vaury C, Bucheton A., Pélisson A., The b-heterochromatic sequences flanking the I elements are themselves defective transposable elements, Chromosoma 98 (1989) 215-224.

[23] Vieira C, Biémont C., Selection against transposable elements in D. simulans and D. melanogaster, Genet. Res. 68 (1996) 9-15.

[24] Vieira C, Biémont C., Geographical variation in insertion site number of retrotransposons 412 in Drosophila simulans, J. Mol. Evol. 42 (1996) 443-451.

[25] Vieira C, Biémont C., Transposition rate of the 412 retrotransposable element is independent of copy number in natural populations of Drosophila simulans, Mol. Biol. Evol. 14 (1997) 185-188.

[26] Young M.W., Schwartz H.E., Nomadic gene families in Drosophila, Cold Spring Harbor Symp. Quant. Biol. 45 (1981) 629-640.

[27] Yuki L., Inouye S., Ishimaru S., Saigo K., Nucleotide sequence characterization of a Drosophila retrotransposon 412, Eur. J. Biochem. 158 (1986) 403-410. 